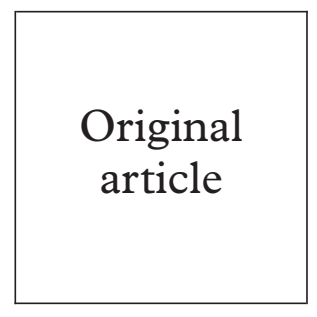

Original article

University

Department of Medical Microbiology and Genitourinary Medicine, 8th Floor, Duncan Building, Daulby Street, Liverpool L69 3GA, UK

O P Arya

C Y W Tong

C A Hart

B C Pratt*

$S$ Hughes

P Roberts

P Kirby

J Howel

University

Department of

Computing Services, Chadwick Tower,

University of

Liverpool, UK

A McCormick

A D Goddard

${ }^{\star}$ Deceased.

Correspondence to: Dr Arya

cahmm@liv.ac.uk

Accepted for publication 10 August 2000

\title{
Is Mycoplasma hominis a vaginal pathogen?
}

\author{
O P Arya, C Y W Tong, C A Hart, B C Pratt, Stella Hughes, Pamela Roberts, \\ Patricia Kirby, Jean Howel, Anne McCormick, A D Goddard
}

Objective: To evaluate the role of Mycoplasma hominis as a vaginal pathogen.

Design: Prospective study comprising detailed history, clinical examination, sexually transmitted infection (STI) and bacterial vaginosis screen, vaginal swabs for mycoplasmas and other organisms, follow up of bacterial vaginosis patients, and analysis of results using sPss package.

Setting: Genitourinary medicine clinic, Royal Liverpool University Hospital.

Participants: 1200 consecutive unselected new patients who had not received an antimicrobial in the preceding 3 weeks, and seen by the principal author, between June 1987 and May 1995.

Main outcome measures: Relation of $M$ hominis isolation rate and colony count to: (a) vaginal symptoms and with the number of polymorphonuclear leucocytes (PMN) per high power field in the Gram stained vaginal smear in patients with a single condition - that is, candidiasis, bacterial vaginosis, genital warts, chlamydial infection, or trichomoniasis, as well as in patients with no genital infection; (b) epidemiological characteristics of bacterial vaginosis.

Results: 1568 diagnoses were made (the numbers with single condition are in parenthesis). These included 291 (154) cases of candidiasis, 208 (123) cases of bacterial vaginosis, 240 (93) with genital warts, 140 (42) chlamydial infections, 54 (29) cases of trichomoniasis, and 249 women with no condition requiring treatment. $M$ hominis was found in the vagina in 341 women, but its isolation rates and colony counts among those with symptoms were not significantly different from those without symptoms in the single condition categories. There was no association between $M$ hominis and the number of PMN in Gram stained vaginal smears whether $M$ hominis was present alone or in combination with another single condition. $M$ hominis had no impact on epidemiological characteristics of bacterial vaginosis.

Conclusion: This study shows no evidence that $M$ hominis is a vaginal pathogen in adults. (Sex Transm Inf 2001;77:58-62)

Keywords: bacterial vaginosis; vaginal pathogens; Mycoplasma hominis

\section{Introduction}

Mycoplasma hominis and Ureaplasma urealyticum are the most frequently isolated mycoplasmas from the human genital tract. They are ubiquitous resulting in colonisation of the genitalia by sexual contact. Taylor-Robinson and McCormack reviewed the genital mycoplasmas in $1980 .{ }^{1}$ A more recent update described the putative roles of these and other species, notably $M$ fermentans, $M$ genitalium, and $M$ penetrans. ${ }^{2}$

$M$ hominis has been linked to pelvic inflammatory disease ${ }^{34}$ and preterm labour. Although frequently isolated in association with bacterial vaginosis, chlamydial and gonorrhoeal infections, and trichomoniasis, ${ }^{5}$ its exact contribution in these conditions remains unclear. On its own it is thought to behave as a commensal. ${ }^{2}$ Nevertheless, $M$ hominis has been isolated in pure culture from cases of vaginitis in children. ${ }^{5}$ We sought to investigate its role by studying women with the above infections as well as women with genital warts and candidiasis comparing those with (including quantitative analysis) and without $M$ hominis. Symptoms, notably vaginal discharge with or without irritation, and an inflammatory response indicated by the number of polymorphonuclear leucocytes (PMN) per high power field (hpf) were noted. To exclude any potential effect of concurrent infection(s), we analysed women with a single condition, as well as women not found to have any condition requiring treat- ment, termed "normal" in this paper. We also investigated the contribution of $M$ hominis, if any, to the epidemiology and aetiology of bacterial vaginosis.

\section{Participants and methods}

The local hospital ethics committee's approval was obtained. The study population comprised all new unselected female patients, who had not received any topical medication or a systemic antimicrobial in the preceding 3 weeks and were seen by one observer (OPA) at the department of genitourinary medicine, the Royal Liverpool University Hospital, between June 1987 and May 1995. After obtaining a detailed history the patients underwent clinical, including genital and pelvic examination. The appearance of the vulva, vagina, cervix, the quality and quantity of discharge, and other physical signs were noted.

\section{Laboratory methods}

CANDIDIASIS

Gram stained vaginal smears were examined for yeast cells and pseudohyphae in the clinic. Swabs were sent in Feinberg-Whittington medium to the laboratory for culture.

\section{BACTERIAL VAGINOSIS}

The tests included vaginal $\mathrm{pH}$, amine test, wet film, and Gram stained smears for clue cells and other morphotypes. Swabs were cultured aerobically and anaerobically on blood, choco- 
late, and MacConkey agars, and on Gardnerella selective medium (Mobiluncus was not specifically sought). The wet films and Gram stained smears were examined in the clinic by technicians blinded to the clinical details. Bacterial vaginosis was diagnosed in the presence of vaginal $\mathrm{pH}>4.5$, a positive amine test, paucity or absence of lactobacilli, and the presence of clue cells. All these patients had a Nugent score $^{6}$ (applied retrospectively up to 1991 and thereafter prospectively) of $>6$.

\section{CHLAMYDIAL INFECTION}

Swabs were taken from the endocervix (and other sites as indicated) and sent in transport media to the hospital laboratory where they were processed using enzyme linked immunosorbent assay (ELISA, AntigEnz Chlamydia, Shield Diagnostics) and immunofluorescence techniques (DIF, Syva Microtrak, Syva).

\section{GONOCOCCAL INFECTION}

Gram stained smears from the endocervix and other sites as indicated were examined in the clinic and swabs were inoculated onto modified Thayer-Martin medium (Oxoid, Basingstoke, $\mathrm{UK}$ ) and cultured at $37^{\circ} \mathrm{C}$ in carbon dioxide in humidified air.

TRICHOMONIASIS

Wet smears from the posterior vaginal fornix were examined in the clinic by microscopy. Swabs were sent in Feinberg-Whittington medium to the laboratory for culture.

\section{MYCOPLASMAS}

Vaginal and endocervical swabs were sent to the laboratory in $\mathrm{A} 3 \times \mathrm{B}$ transport medium. ${ }^{7}$ These were inoculated into PPLO broths (Difco) in serial 10-fold dilutions. $U$ urealyticum broth contained $1 \%(\mathrm{w} / \mathrm{v})$ urea at $\mathrm{pH} 6.0$ and $M$ hominis broth contained $1 \%(\mathrm{w} / \mathrm{v})$ arginine dihydrochloride at $\mathrm{pH}$ 7.4. Both contained $0.002 \%(\mathrm{w} / \mathrm{v})$ phenol red indicator. ${ }^{8}$ Broths showing colour change after incubation at $37^{\circ} \mathrm{C}$ for $4-5$ days were subcultured onto $\mathrm{A} 7$ mycoplasma $\operatorname{agar}^{7}$ for confirmation. The amount of $M$ hominis in a sample was determined by end point titration in broth and expressed as number of colony forming units (CFU) per ml. A CFU of $\geqslant 5 \times 10^{5} / \mathrm{ml}$ indicated the presence of the organism in large numbers.

\section{STATISTICAL ANALYSIS}

The results were analysed using the sPss package (Statistical Package for Social Sciences).

The differences between the various categories

Table $1 M$ hominis isolation rates in the various diagnostic categories

\begin{tabular}{|c|c|c|c|}
\hline Category & $\begin{array}{l}\text { No with single } \\
\text { conditions }\end{array}$ & $\begin{array}{l}\text { No with } M \\
\text { hominis (\%) }\end{array}$ & $\begin{array}{l}\text { No with } M \text { hominis } \\
\text { count } \geqslant 5 \times 10^{5}(\% \text { of } \\
\text { those with } M \text { hominis) }\end{array}$ \\
\hline Candidiasis & 154 & $12(8 \%)$ & $5(42 \%)$ \\
\hline Bacterial vaginosis & 123 & $73(59 \%)$ & $35(48 \%)$ \\
\hline Genital warts & 93 & $19(20 \%)$ & $8(42 \%)$ \\
\hline Chlamydial infection & 42 & $13(31 \%)$ & $6(46 \%)$ \\
\hline Trichomoniasis & 29 & $17(59 \%)$ & $13(76 \%)$ \\
\hline Normal & 249 & $31(12 \%)$ & $7(23 \%)$ \\
\hline All women (1200) & & $341(28 \%)$ & $156(46 \%)$ \\
\hline
\end{tabular}

were assessed using the $\chi^{2}$ test or Fisher's exact test (if cell values less than 5) using EPI-INFO version 6 (CDC, Atlanta, GA, USA).

\section{Results}

A total of 1200 patients were enrolled. A total of 1568 diagnoses were made (numbers with single condition in parentheses), including 291 (154) of candidiasis, 208 (123) of bacterial vaginosis (BV), 240 (93) of genital warts, 140 (42) chlamydial infections, 54 (29) with trichomoniasis (TV), and 249 "normal" women with no condition requiring treatment. $M$ hominis was found in the vagina in 341 women.

\section{HOMINIS ISOLATION RATES}

$M$ hominis isolation rates and of those with high numbers $\left(\geqslant 5 \times 10^{5}\right)$ among women with single conditions, and of the "normal" category, and all women are shown in table 1. M hominis isolation rates were highest among those with BV and TV $(59 \%)$ followed by those in the chlamydia category $(31 \%)$, warts $(20 \%)$, the normal category $(12 \%)$, and candidiasis $(8 \%)$. The differences between TV and normal categories, and BV and normal categories were highly significant $(p<0.0001)$. The difference between those with chlamydial infection and the normal category was also significant $(\mathrm{p}=$ $0.0041)$. Women with TV who also had $M$ hominis had the highest rate $(76 \%)$ of $M$ hominis high counts followed by those with BV $(48 \%)$, compared with the normal category $(23 \%)$. Using high colony counts alone, only the differences between TV and normal categories and between BV and normal categories remained significant ( $\mathrm{p}$, respectively, 0.0009 and 0.0283 ).

\section{VAGINAL DISCHARGE}

Table 2 shows the numbers and proportions of women who complained of, or admitted to experiencing, vaginal discharge with or without vaginal or vulval irritation in the various categories. In all categories, except candida, more of $M$ hominis positive women had experienced vaginal discharge than the $M$ hominis negative women. However, the difference was statistically significant only between the overall totals within the whole populations studied. Thus 36\% (312 of 859) of $M$ hominis negative women had symptoms of vaginal discharge compared with 58\% (199 of 341) of $M$ hominis positive $(\mathrm{p}<0.00001)$. The presence of $M$ hominis in large numbers $\left(\geqslant 5 \times 10^{5}\right)$ did not seem to have any additional effect.

INFLAMMATORY RESPONSE IN THE VAGINA

Table 2 shows the "inflammatory response" as indicated by the presence of more than 20 PMN per hpf in the Gram stained vaginal smears in the various diagnostic categories. No significant differences between $M$ hominis positive and $M$ hominis negative women were detected in all "single condition" categories. However, when all women were considered, $21 \%$ (179 of 859) of $M$ hominis negative women had inflammatory response compared 


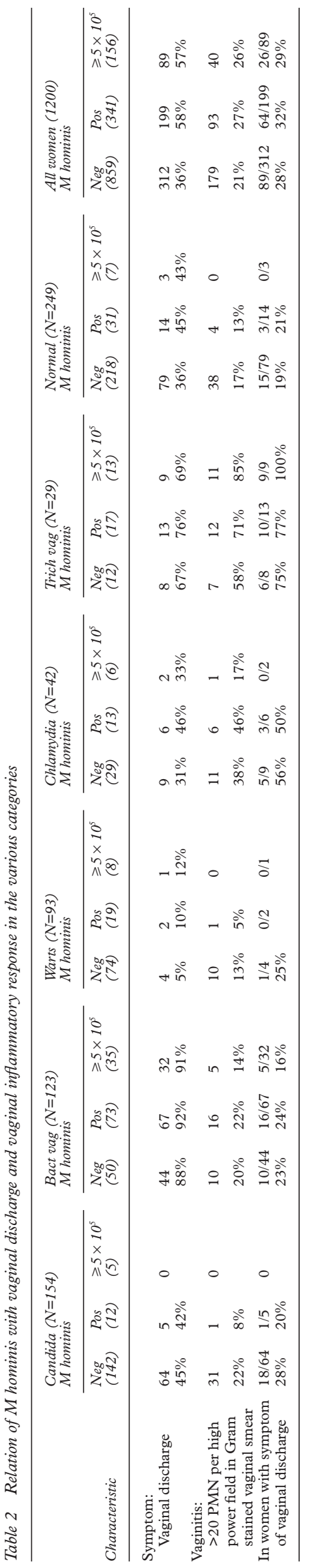

with $27 \%$ (93 of 341) in $M$ hominis positive women; this difference was statistically significant $(\mathrm{p}=0.02)$.

We also looked at the vaginal inflammatory response as defined above in the various diagnostic categories in the presence of vaginal discharge as a symptom; the differences between those who were $M$ hominis positive and those $M$ hominis negative within the various categories were very small and not significant (table 2).

\section{HOMINIS AND BACTERIAL VAGINOSIS}

Epidemiology

Table 3 shows the epidemiological characteristics of the BV and the "normal women" categories (because of the aetiological association of Gardnerella vaginalis and strict anaerobes with BV, women with these organisms in vaginal swab cultures have been excluded from the normal women category). Only one characteristic emerged to be noteworthy - that is, the use of an intrauterine contraceptive device (IUCD); $14(24 \%)$ of the $58 M$ hominis positive women were using IUCD compared with only two (5\%) of the $40 \mathrm{M}$ hominis negative women in the BV category. This difference was significant $(p=0.025)$. The significance level in this respect was higher when $M$ hominis negative women (two of 40) were compared with those with high counts of $M$ hominis (10 of 27) ( $\mathrm{p}=$ 0.002). However, no such difference was observed in the normal women category. Indeed, none of the $12 \mathrm{M}$ hominis positive women in the normal women category was using IUCD suggesting that the difference noted above in the BV category was not due to $M$ hominis alone. The differences between $M$ hominis negative and $M$ hominis positive women with regard to all the other factors in the normal women category were also not significant.

\section{Aetiology}

Table 4 compares patients in the BV category with the normal women category of women with regard to the associations between the organisms (that is, $M$ hominis, $G$ vaginalis, and strict anaerobes) and BV. Although $M$ hominis alone was isolated more often from women in the normal women category (14 of $249,6 \%$ ) than from those in the BV category (four of $123,3 \%)$, this difference was not significant ( $p$ $=0.4559)$. Two of the four women with $M$ hominis alone in the $\mathrm{BV}$ category, compared with two of the 14 women in the normal women category had $M$ hominis colony counts of $\geqslant 5 \times 10^{5}$; this difference was not significant ( $\mathrm{p}=0.1970)$. Of the 86 women harbouring $G$ vaginalis and/or strict anaerobes as well as $M$ hominis, 69 (80\%) had BV compared with 46 $(73 \%)$ of 63 women with $G$ vaginalis and/or strict anaerobes but without $M$ hominis. The difference was, however, not significant $(\mathrm{p}=$ 0.4012 ), suggesting that the additional presence of $M$ hominis with $G$ vaginalis and strict anaerobes did not seem to increase the likelihood of the patient developing BV. 
Table 3 Epidemiological characteristics of bacterial vaginosis and "normal women" categories

\begin{tabular}{|c|c|c|c|c|c|c|}
\hline \multirow[b]{2}{*}{ Epidemiological characteristic } & \multicolumn{3}{|c|}{ Bacterial vaginosis (123) $M$ hominis } & \multicolumn{3}{|c|}{ "Normal women" (215)* $M$ hominis } \\
\hline & $\operatorname{Neg}(50)$ & Pos (73) & $\geqslant 5 \times 10^{5}(35)$ & Neg (201) & $\operatorname{Pos}(14)$ & $\geqslant 5 \times 10^{5}(2)$ \\
\hline Mean age & 27.20 & 27.97 & 27.54 & 26.16 & 26.64 & 25.5 \\
\hline Mean age first sex & 17.26 & 17.59 & 17.77 & 17.44 & 18.21 & 19.0 \\
\hline \multicolumn{7}{|l|}{ Marital status: } \\
\hline Single & $30(60 \%)$ & $46(63 \%)$ & $23(66 \%)$ & $145(72 \%)$ & $11(79 \%)$ & 2 \\
\hline Currently married & $10(20 \%)$ & $12(16 \%)$ & $3(8 \%)$ & $44(22 \%)$ & $1(7 \%)$ & 0 \\
\hline Divorced/widowed/separated & $10(20 \%)$ & $15(20 \%)$ & $9(26 \%)$ & $12(6 \%)$ & $2(14 \%)$ & 0 \\
\hline Last sex in past 2 weeks & $34(68 \%)$ & $43(59 \%)$ & $16(46 \%)$ & $119 / 200(60 \%)$ & $8(57 \%)$ & 1 \\
\hline Positive history of cunnilingust: & $27 / 38(71 \%)$ & $27 / 45(60 \%)$ & $8 / 17(47 \%)$ & $95 / 137(69 \%)$ & $5 / 8(63 \%)$ & 0 \\
\hline Never pregnant & $24(48 \%)$ & $24(33 \%)$ & $10(29 \%)$ & $111(55 \%)$ & $7(50 \%)$ & 0 \\
\hline More than 1 sex partner past 12 months & $14(28 \%)$ & $17(23 \%)$ & $11(31 \%)$ & $50 / 200(25 \%)$ & $6(43 \%)$ & 0 \\
\hline \multicolumn{7}{|l|}{ Last menstrual period:: } \\
\hline$\leqslant 9$ days ago & $7 / 47(15 \%)$ & $13 / 66(20 \%)$ & $4 / 30(13 \%)$ & $29 / 190(15 \%)$ & $4 / 14(28 \%)$ & 1 \\
\hline $10-19$ days ago & $22 / 47(47 \%)$ & $32 / 66(48 \%)$ & $15 / 30(50 \%)$ & $89 / 190(47 \%)$ & $5 / 14(36 \%)$ & 1 \\
\hline$>19$ days ago & $18 / 47(38 \%)$ & $21 / 66(32 \%)$ & $11 / 30(37 \%)$ & $72 / 190(38 \%)$ & $5 / 14(36 \%)$ & 0 \\
\hline \multicolumn{7}{|l|}{ Contraception§: } \\
\hline Hormone & $19 / 40(47 \%)$ & $21 / 58(36 \%)$ & $7 / 27(26 \%)$ & $83 / 175(47 \%)$ & $7 / 12(58 \%)$ & 1 \\
\hline IUCD & $2 / 40(5 \%)$ & $14 / 58(24 \%)$ & $10 / 27(37 \%)$ & $6 / 175(3 \%)$ & $0 / 12$ & 0 \\
\hline None & $7 / 40(17 \%)$ & $10 / 58(17 \%)$ & $3 / 27(11 \%)$ & $29 / 175(17 \%)$ & $2 / 12(17 \%)$ & 0 \\
\hline \multicolumn{7}{|l|}{ Condom: } \\
\hline Sometimes & $4(8 \%)$ & $7(10 \%)$ & $4(11 \%)$ & $14(7 \%)$ & 0 & 0 \\
\hline Always & $2(4 \%)$ & $5(7 \%)$ & $2(6 \%)$ & $31(15 \%)$ & 0 & 0 \\
\hline Smoker: & $25(50 \%)$ & $42(57 \%)$ & $21(60 \%)$ & $84(42 \%)$ & $5(36 \%)$ & 0 \\
\hline Partner circumcisedt: & $3 / 37(8 \%)$ & $3 / 44(7 \%)$ & 0 & $10 / 120(8 \%)$ & $3 / 10(30 \%)$ & $1 / 2$ \\
\hline
\end{tabular}

*Women with $G$ vaginalis/anaerobes in vaginal swab cultures have been excluded.

tInformation not available for some patients; hence denominator shown.

$\ddagger$ Pregnant, hysterectomised, and menopausal women have been excluded.

§Pregnant, hysterctomised, and menopausal women and those with vasectomised husbands have been excluded.

Table 4 Association of $M$ hominis, $G$ vaginalis, and anaerobes with bacterial vaginosis

\begin{tabular}{lcc}
\hline Organisms & BV category & $\begin{array}{c}\text { "Normal women" } \\
\text { category }\end{array}$ \\
\hline None & $4(3 \%)$ & $201(81 \%)$ \\
$M$ hominis only & $4(3 \%)$ & $14(6 \%)$ \\
$G$ vaginalis only & $4(3 \%)$ & $6(2 \%)$ \\
Anaerobes only & $4(3 \%)$ & $3(1 \%)$ \\
$G$ vaginalis and anaerobes & $38(31 \%)$ & $8(3 \%)$ \\
$M$ hominis and $G$ vaginalis & $4(3 \%)$ & $6(2 \%)$ \\
$M$ hominis and anaerobes & $2(2 \%)$ & $2(1 \%)$ \\
$G$ vaginalis, anaerobes, and $M$ hominis & $63(51 \%)$ & $9(4 \%)$ \\
& 123 & 249 \\
\hline
\end{tabular}

\section{Discussion}

To our knowledge this is the first large prospective study to investigate the role of $M$ hominis as a vaginal pathogen in adults. One of us (OPA) undertook all the clinical examinations and sample collections thus avoiding the problems of interobserver variation. However, we acknowledge that this study has certain limitations. Firstly, the conventional diagnostic methods used in this study (as opposed to those increasingly being used now encompassing DNA technology, particularly for chlamydial infection) would not with certainty have excluded some of the concurrent infections. This may, possibly, be at least partly responsible for our finding of inflammatory response in a fifth of our patients with BV. Nevertheless, this potential bias would apply equally to all of the diagnostic categories. Secondly, having had to exclude the concurrent infections to make meaningful comparisons, the resulting number became rather small. This we deem, however, to be the correct approach in view of the significant differences found between $M$ hominis positive and $M$ hominis negative women among the total population, suggesting the potential role of concurrent infection(s). This reinforces the importance of taking steps to eliminate such potential influences when assessing the role of $M$ hominis.
The above limitations notwithstanding, this study confirms the frequent isolation of $M$ hominis in bacterial vaginosis, chlamydial infection, and trichomoniasis. The low rate of $M$ hominis carriage in women with candidiasis has been observed previously, ${ }^{9}$ and is partly due to the low $\mathrm{pH}(\leqslant 4.5)$ as well as low rates of anaerobes in women with candidiasis, both these features being unfavourable to $M$ hominis $^{10}{ }^{11}$ ( $85 \%$ of our patients in the candida category had vaginal $\mathrm{pH} \leqslant 4.5$ and only $12 \%$ had $G$ vaginalis and/or strict anaerobes in the vaginal swabs). The presence of $M$ hominis, however, did not influence the symptom of vaginal discharge or the number of PMN in Gram stained vaginal smears whether $M$ hominis was present without or in combination with another condition. It has been suggested that relapse after treatment of BV with metronidazole may be the result of this drug being inactive against $M$ hominis. ${ }^{12}$ Previously, however, a study using a therapeutic approach to assess the cause of non-specific vaginitis (now termed bacterial vaginosis) had shown that, whereas eradication of $G$ vaginalis (when patients treated with metronidazole) cleared vaginitis, eradication of $M$ hominis alone (when patients treated with doxycycline) did not, ${ }^{13}$ raising doubts over the role of $M$ hominis in BV.

In addition, $M$ hominis did not seem to make any contribution to the epidemiology of bacterial vaginosis. In this context, the exclusion of those harbouring $G$ vaginalis and strict anaerobes in the vagina from the normal women category (table 3) may be debatable. We have already given a reason for this to which may be added the possibility that vaginal colonisation with $M$ hominis may in part be dependent on vaginal anaerobes. ${ }^{11}$ In a recent study $M$ hominis was reported to be more strongly associated with bacterial vaginosis than $G$ vaginalis. ${ }^{14}$ Our findings do not support this. That study, however, did not take the other anaer- 
obes into account; nor is it clear as to whether or not the concurrent infections were excluded. Taylor-Robinson and $\mathrm{McCormack}^{1}$ surmised $M$ hominis may act either in symbiosis with other organisms or as a sole pathogen in bacterial vaginosis. In our study $M$ hominis did not display an active role in either capacity.

Conflict of interest: None

Some preliminary results, while the study was still in progress, were presented at the Spring Meeting of the Medical Society for the Study of Venereal Diseases held in Liverpool in May 1994.

We are indebted to the staff of the department of genitourinary medicine and medical microbiology, Royal Liverpool University Hospital for their kind cooperation at all times. pool University Hospital for their kind cooperation at all times.
We thank M Blake who carried out the mycoplasma laboratory We thank M Blake who carried out the mycoplasma laboratory
work, Dr L Cuevas of the Liverpool School of Tropical work, Dr L Cuevas of the Liverpool School of Tropical
Medicine for statistical advice, and Clare Kelly and Lynda Jones
for typing the manuscript.

for typing the manuscript.

Contributors: OPA had the original idea for the study and designed the protocol, recruited and examined patients and completed proformas, collected and interpreted data, carried out and completed statistical analysis, and was the principal uthor of the paper; BCP (deceased) participated in the protocol design and supervised the laboratory work on chlamydia and mycoplasma, taken over later by CYWT, who, in addition, par-
ticipated in the interpretation of data and review of the manuscript; $\mathrm{CAH}$ supervised the laboratory work on the remaining aspects of bacteriology and participated in the
interpretation of data and manuscript reviews; SH, PR, PK, and $\mathrm{JH}$ carried out all the laboratory work in the genitourinary medicine department clinic; AMCC and ADG processed and extracted the data in a form that could be easily analysed.

1 Taylor-Robinson D, McCormack WM. The genital mycoplasmas. N Engl F Med 1980;302:1003-10.

2 Taylor-Robinson D, Furr PM. Update on sexually transmitted mycoplasmas. Lancet 1998;351:sm12-15.
3 Mardh P-A, Westrom L. Tubal and cervical cultures in acute salpingitis with special reference to Mycoplasma hominis and T-strain mycoplasmas. Br F Vener Dis 1970;46: 179-86.

4 Mardh P-A, Westrom L. Antibodies to Mycoplasma hominis in patients with genital infections and in healthy controls. Br F Vener Dis 1970;46:390-7.

5 Taylor-Robinson D. Clinical significance of genital chlamydial and mycoplasmal infections. In: Csonka GW, Oates JK, eds. Sexually transmitted diseases. London: Bailliere TinJK, eds. Sexually tran
dall, 1990:19-38.

6 Nugent RP, Krohn MA, Hillier SL. Reliability of diagnosing bacterial vaginosis is improved by a standardised method of Gram stain interpretation. F Clin Microbiol 1991;29:297301.

7 Shepard MC, Lunceford CD. Differential agar medium (A7) for identification of Ureaplasma urealyticum (human T mycoplasmas) in primary cultures of clinical material. 7 Clin Microbiol 1976;3:613-25.

8 Mardh P-A. Bacteria, chlamydiae and mycoplasmas. In: Holmes KK, Mardh P-A, Sparling PF, Wiesner PJ, eds. Sexually transmitted diseases. New York: McGraw-Hill, 1984:829-56.

9 Holst E, Wathne B, Hovelius B, et al. Bacterial vaginosis: microbiology and clinical findings. Eur $\mathcal{f}$ Clin Bacteriol 1987;6:536-41

10 Paavonen J, Miettinen A, Stevens CE, et al. Mycoplasma hominis in nonspecific vaginitis. Sex Transm Dis 1983; 10(suppl):271-275.

11 Koutsky LA, Stamm WE, Brunham RC, et al. Persistence of $M$ hominis after therapy: importance of tetracycline resistance and of co-existing vaginal flora. Sex Transm Dis 1983;10(suppl):374-81.

12 Dawson S. Bacterial vaginosis. In: Csonka GW, Oates JK, eds. Sexually transmitted diseases. London: Bailliere Tindall, 1990:299-304.

13 Pheifer TA, Forsyth PS, Durfee MA, et al. Nonspecific vaginitis: role of Haemophilus vaginalis and treatment with metronidazole. N Engl f Med 1978;298:1429-34.

14 Lamont RF. In: Easmon CSF, ed. The diagnosis and management of bacterial vaginosis. London: Royal Society of Medicine, 1993:34-9. 